\title{
Uncloaking the black art
}

$\mathrm{W}$ hen Dr. Brian Goldman decided to decode the slang that medical professionals use to talk about patients and colleagues, he wanted to spark debate.

Goldman hopes readers of The Secret Language of Doctors: Cracking the Code of Hospital Slang won't focus solely on the derogatory slang but that they will also learn from his explanation of its origins: the pressures that give birth to the words. Only then, he believes, will we be able to address the underlying problems.

"I had hoped that people would hear in the slang that [health professionals] are complex individuals and that we have, like everybody else, things that frustrate us about trying to deliver health care with an increasing population of chronically ill patients, who, despite our best efforts, continue to return again and again to hospital with their problems not solved," says Goldman.

In an interview from Toronto, where he is an emergency department physician at Mount Sinai Hospital and host of the CBC radio show "White Coat, Black Art," Goldman explains that it is critically important that health care leaders listen for and learn from the slang that is prevalent in hospitals, in Canada and the United States.

But if the readers of The Secret Language of Doctors are patients, they may well be sidetracked from Goldman's underlying purpose by the breathtaking lack of compassion on the part of some health care professionals.

Some doctors, nurses and residents refer to an obese patient as a "beached whale," a "seal" or a "beemer," a reference to the patient's body mass index. Others refer to an overweight patient with cirrhosis of the liver as a "yellow submarine." An older patient who is awaiting placement in a long-term care facility as a "bed blocker" suffering from "failure to die." A homeless person with no measurable physical problem may be called a "CLL — chronic low-life." And someone who visits the hospital over and over again with a chronic condition they are not taking

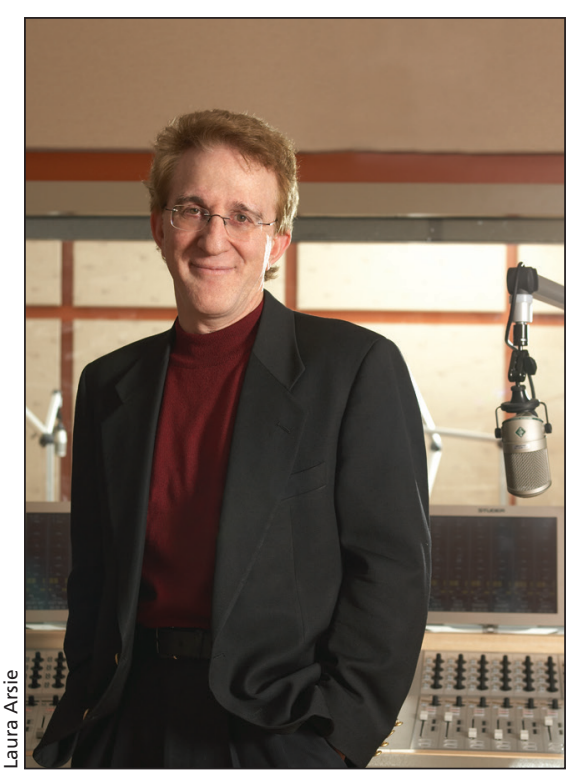

Brian Goldman hopes his book reveals "the pressures that give birth to the words."

steps to improve may be called a "cockroach."

Many doctors, he says, are not, "either by interest, inclination, training or experience," well-prepared to treat the increasing number of senior, Aboriginal, mentally ill, indigent or chronically ill patients with no access to good primary or preventive health care who show up in hospital emergency departments.

"To me, the slang reveals the frustration, and so points the way to what we'e frustrated with and the issues we need to address," Goldman says.

Really? As a patient, it's difficult to believe that better training or even improvements to the health system are all that's required to prompt some health care professionals to start referring to patients with basic respect and understanding.

Goldman's colleagues may apply slang to themselves as well, to indicate the hierarchy, competition and rivalry among physicians, residents, interns and nurses. Emergency physicians are dubbed "triage nurses" or "referologists," surgeons are "cowboys," internists are "fleas."

Many of these nicknames, acronyms and slang (like "code brown" for a bowel movement) are simply illustrations of the black humour health care professionals use to lighten their load, Goldman says.

But other examples point to a serious lack of empathy among health care professionals, for their patients and for each other, Goldman says. He hopes the book will get people talking openly about necessary reforms, including lifts and bigger stretchers for overweight patients, and clinics in the neighbourhoods of patients identified as the most frequent users of emergency care.

Goldman's mission, as a doctor, broadcaster and writer, is to pull back the curtain on the often shrouded world of medicine. 'I don't just want to make [patients] skeptical, I want to make you more informed, I want you to ask questions."

Deciphering the secret code may not make him beloved by his colleagues but that's too bad, Goldman says, the shrug almost visible in his voice.

His mother's long descent into dementia and his elderly father's heart attack and death have given him an entirely new appreciation of what it's like to be a consumer of hospital care, and that is part of what drove him to write this exposé.

The actual writing was fuelled by Goldman's lifelong insomnia, which he has turned into a gift rather than a trial. By rising early every day and writing until 8:00 am, he is able to juggle his journalistic career with his emergency department shifts.

Goldman says the best lesson he has gleaned is to learn from mistakes or "hard conversations" with patients or their families who have told him the unvarnished truth about an encounter where he did not exhibit the empathy they deserved. He hopes The Secret Language of Doctors will begin those same difficult conversations — with positive results.

\section{Laura Eggertson BA BJ}

Journalist

Ottawa, Ont.

CMAJ 2014. DOI:10.1503/cmaj.140661 